

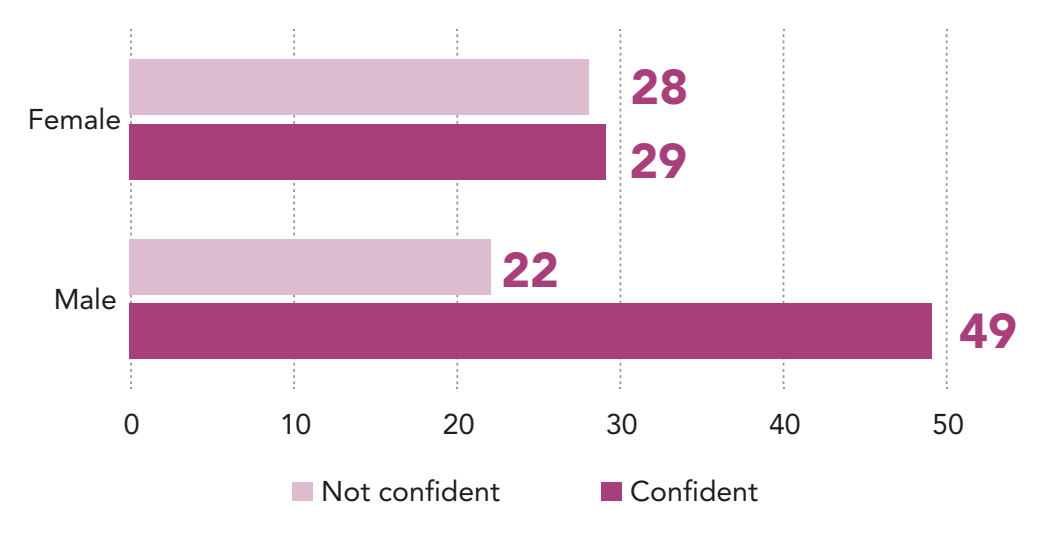

Figure 4. Confidence in solving non-routine problems, by gender

50-minute lectures per week. In the middle FINDINGS of each lecture, the lecturer would ask students to attempt to solve an unfamiliar non-routine problem. These non-standard, unstructured questions were presented in an entertaining way and the students were free to work individually or in small groups. follow with the activity saking $2-5$ minutes to complete.

At the end of the semester, a student survey was conducted in class in the form of a paper-based questionnaire made up of ten questions. Three questions were on demographics, with the others exploring the interplay between the students lateral thinking self-efficacy, performance, gender, prior achievement, together with their feelings, beliefs and attitudes towards non-routine problem solving. The students were encouraged to provide open-ended answers together with any unsolicied comments that they wanted to add. In total 137 students (81 males, 53 females, 3 unidentified) from two secondthe study with a response rate of $97 \%$ of those present.

A sequential two-phase data analysis approach was used so as to reduce reliance on Likert-style instruments and move toward a greater use of narratives.
The first phase involved the qual itative analysis of students' responses to ascertain their views on various aspects of the intervention. The second phase involved the use of a quantitative technique to investigate frequency counts for each of the themes identified in phase one. From these, the relative frequency of differential responses to the phase one themes from students wi high versus low lateral thing
efficacy was determined.

The results suggest that the attitude profiles of students with high and low lateral thinking self-efficacy differ (vision; enhancement utility; and emo domain. The affective doman descibes high lateral thinking self-efficacy had with low lateral thinking self-efficacy. high lateral thinking self-efficacy had

Interestingly, the students' prior performance in mathematics did not appear to affect their confidence in solving non-routine problems. There was, however, a significant associto solving non-routine problems and their performance in solving them. The study uncovered a significant difference between genders when latera Although there was no significant association between gender and nonroutine problem-solving performance, there was a significantly greater proportion of confident males than females. The researchers note that these results raise questions about equity with regard to employability prospects for females in STEM companies. Moreover, this may explain the 'leaky-pipeline' phenomenon that is evident in the underrepresentatio of women in STEM fields. significantly towards non-routine problem solving with respect to three dimensions people's attitudes to capture how they deal with things emotionally and includes their feelings, beliefs, motivations and values.

The analysis revealed that significantly fewer students with high lateral thinking self-efficacy viewed non-routine problem

\section{ROADER IMPLICATIONS}

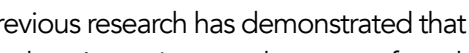
'students' emotions can have a profound and perfor their academic engagentive and negative moods on problem solving has also been obsenved Experiments suggest that a positive mood promotes flexible, creative, and holistic ways of solving problems, with students relying on generalised, heuristic knowledge structures. Taking these considerations

\section{Although there was no significant} association between gender and nonroutine problem-solving performance, there was a significantly greater proportion of confident males than females.

solving as a challenge when compared with those with low lateral thinking selfefficacy. Significantly more students with positive emotional dispositions towarc
non-routine problem solving than those Likewise, significantly more students with positive ratings on both the Enjoymen theme and the Engagement theme than those with low lateral thinking self-efficacy. together with the findings of this study, the research team postulate that targeting
an activation of positive emotions during the stages of non-routine problem solving could improve lateral thinking self-efficacy. They also suggest that ensuring that future graduates' experience the enjoyment of understanding a solution, rather than feeling frustrated when a solution their epistemic emotions during similar interventions.

Further research into non-routine problem solving in STEM education, funded by the (New Zealand), is being conducted by a larger team
Klymchuk. is not explained well, would moderate Teaching and Learning Research Initiative

\section{Behind the Research}

) Dr Tanya Evans

E: t.evans@auckland.ac.nz T: +649238783 W: https://unidirectory.auckland.ac.nz//profile/t-evans

\section{Research Objectives}

The research team have designed an intervention to examine whether employability prospects for STEM students studying mathematics could be improved.

\section{Detail}

\section{Address}

Tanya Evans

Department of Mathematics

University of Auckland

Sergiy Klymchuk

Engineering, Computer \& Mathematical

Auckland University of Technology

Tanya Evans is a lecturer at the Department of Mathematics, University of Auckland. Her research is

in the moderniction of higher education

\section{References}

Evans, T., Thomas, M. \& Klymchuk, S. (2020). Non-routine problem solving through the lens of self-efficacy. Higher Education Research \& Development Available at: https://doi org/10.1080/07294360.2020.1818061

Evans, T., Klymchuk, S., Murphy, P. E. L., Novak, J., Stephens, J., \& Thomas, M. (2020). Engagement of undergraduate STEM students: the influence of non-routine problems. Highe Education Research \& Development, 1-17. Available at: https://doi.org/10.1080/07294360.2020.1835838

Pugh, K., \& Bergin, D. (2006). Motivational influences on transfer. Educational Psychologist, 41(3), 147-160. Avaliable at: https://doi.org/10.1207/s15326985ep4103_2

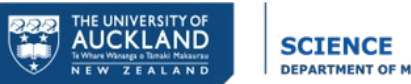
Aाएँ

Prof Mike

Thomas

utilising advances in cognitive science on the Higher Edychology. She serves Development Society of Australasia (NZ) ( Mathematics Society Education Group.

Mike Thomas is Emeritus Professor of Mathematics Education, Auckland publications apply versatile mathematic thinking and digital technology to learning mathematics. He has given two fICME-12 lectures, been a member

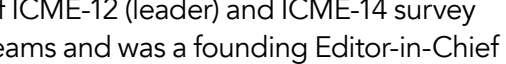

Personal Response

What initially sparked your interest in the relationship Wout self-efficacy?

II Dr Evans: My interest in this topic is rooted in a wellthat studying mathematics equips learners with problem solving skills in a broad sense. On the other hand, there is plenty of evidence from employers complaining about the lack of creativity in problem solving of never-before-seen problems by mathematics and computer science graduates.
These students tend to get fixated on rigorous and precise solutions disregarding contextual requirements that make this approach unsuitable. This inability to be flexible and creative is related to the problem of transfer that has not been well understood in the context of mathematics at a hrough a novel construct - lateral thinking self-efficace an attempt to capture learners' confidence in their ability to
solve non-routine problems. 